\title{
Aprendizagem da docência em atividade de ensino no clube de matemática
}

\author{
Vanessa Dias Moretti \\ Universidade Federal de São Paulo - SP
}

\begin{abstract}
Resumo
Com base na Teoria Histórico-Cultural, nas proposições gerais de Vigotski acerca do caráter social do psiquismo humano e no conceito de atividade aprofundado por Leontiev, a pesquisa investigou a aprendizagem de elementos da docência da Matemática em estudantes de Pedagogia que participaram do Clube de Matemática em uma universidade pública paulista. Os dados analisados foram produzidos pelos sujeitos na forma de portfólio reflexivo individual e relatório final coletivo. A análise dos dados revela que a transformação coletiva das atividades desencadeada pelas necessidades postas aos sujeitos vincula-se ao movimento de atribuição de novos sentidos à reorganização de ações e sua relação com o planejamento, à relação do sujeito com o ensino da Matemática, à relação entre a teoria e a prática na organização do ensino e às condições objetivas do trabalho do professor. Assim, aponta para o movimento de formação docente em atividade de ensino no Clube de Matemática.
\end{abstract}

Palavras-chave: Formação de professores; ensino de matemática; Psicologia Histórico-Cultural.

\section{Learning to teach thorugh activity in the mathematics club}

\begin{abstract}
Based on the Historical-Cultural theory and on Vygotsky's general propositions about the social nature of the human psyche and the concept of activity deepened by Leontiev, we have investigated elements of the learning of Mathematics teaching in Pedagogy students who participated in the Mathematics Club at a public university in São Paulo. The data analyzed were produced by the subjects in the form of individual reflective portfolio and collective final report. Data analysis reveals that the transformation of collective activities, triggered by the needs placed upon the subject, is linked to the movement of assigning new meanings to the reorganization of actions and their relation to the planning, the subject's relation to the teaching of mathematics, the relationship between theory and practice in teaching organization, and objective conditions of the teacher's work. Thus, it points to the movement of teacher training in teaching activity in the Mathematics Club.
\end{abstract}

Keywords: Teacher education; mathematics education; Historic-Cultural Psychology.

\section{Aprendizaje de la docencia en actividad de enseñanza en el club de} matemáticas

\section{Resumen}

Con base en la Teoría Histórico-Cultural, en las proposiciones generales de Vygotsky acerca del carácter social del psiquismo humano y en el concepto de actividad profundizado por Leontiev, el estudio investigó el aprendizaje de elementos de la docencia de la Matemáticas en estudiantes de Pedagogía que participaron del Club de Matemáticas en una universidad pública paulista. Los datos analizados fueron producidos por los sujetos en la forma de portfolio reflexivo individual e informe final colectivo. El análisis de los datos muestra que la transformación colectiva de las actividades desencadenada por las necesidades puestas a los sujetos se vincula al movimiento de atribución de nuevos sentidos a la reorganización de acciones y su relación con el planeamiento, a la relación del sujeto con la enseñanza de la Matemáticas, a la relación entre la teoría y la práctica en la organización de lo enseñanza y a las condiciones objetivas del labor del profesor. Así, apunta para el movimiento de formación docente en actividad de enseñanza en el Club de Matemáticas.

Palabras-clave: la formación del profesorado; enseñanza de matemáticas; Psicología Histórico-Cultural. 


\section{Introdução}

A questão da formação docente tem sido indicada, com recorrência, como fator determinante da qualidade de ensino e das possibilidades de aprendizagem dos estudantes dos diferentes níveis de ensino. Não raramente esse tema emerge de forma leviana nos apontamentos da mídia quando da divulgação dos resultados de avaliações externas realizadas nos espaços escolares como o Exame Nacional do Ensino Médio (ENEM), o Sistema de Avaliação da Educação Básica (SAEB) e, no caso do Estado de São Paulo, o Sistema de Avaliação de Rendimento Escolar do Estado de São Paulo (SARESP).

Esse movimento, se por um lado, ao ignorar a complexidade da realidade escolar e das condições de trabalho docente, aponta a culpabilização do professor pelos ainda baixos índices de aprendizagens obtidos pelos estudantes em tais instrumentos, por outro, tem expandido a preocupação com a formação docente para além do ambiente acadêmico, no qual já é estudado e tomado como problema de investigação há várias décadas.

Assumindo a relevância da temática, porém tendo certeza da necessidade de elementos teóricos que permitam a compreensão desse fenômeno, desenvolvemos ações de pesquisa que tiveram por objetivo investigar a aprendizagem de elementos da docência em Matemática em estudantes do curso de Pedagogia que participaram do Clube de Matemática de uma universidade pública paulista durante o segundo semestre de 2011. Essa investigação focou o processo de apropriação, pelos futuros professores, dos modos de ação docente para a organização do ensino, tendo como referencial teórico para o desenvolvimento das ações de pesquisa as contribuições da Teoria Histórico-Cultural, partindo das proposições gerais de Vigotski acerca do caráter social do psiquismo humano (Vigotski, 2000; 2002; Vygotski, 2000) e, em particular, do conceito de atividade aprofundado por Leontiev (Leontiev, 1983).

Como elemento essencial de sua teoria, Vigotski indica a mediação como eixo estruturante da constituição das funções psicológicas superiores, que são especificamente humanas. De acordo com Asbahr (2011, p.25), a proposta vigotskiana consiste em "compreender os fenômenos psicológicos enquanto mediações entre a história social e a vida concreta dos indivíduos", o que levou Vigotski a formular conceitos sobre "o caráter material do psiquismo humano, o papel da atividade na constituição psíquica e o caráter mediatizado do psiquismo", como afirma Asbahr (2011, p.26).

Acerca da relação entre o papel mediatizado do psiquismo humano e o papel da atividade na constituição psíquica, Vigotski (2002) afirma que no desenvolvimento da criança "o momento de maior significado do desenvolvimento intelectual, que dá origem às formas puramente humanas de inteligência prática e abstrata, acontece quando a fala e a atividade prática, então duas linhas completamente independentes de desenvolvimento, convergem" (p. 33).

O conceito de atividade na perspectiva histórico-cultural tem sua base no conceito de atividade humana an- corado na teoria marxista que toma como central o conceito de trabalho em sua dimensão ontológica, em que este é entendido como atividade humana intencional. Assim, "nessa perspectiva, o trabalho é aquilo que fundamentalmente humaniza e possibilita o desenvolvimento da cultura" (Moretti, Asbahr, \& Rigon, 2011, p. 478).

Tomado como objeto de investigação por Leontiev (1983), o conceito psicológico de atividade diferencia-se daquele do senso comum, que o entende como sinônimo de ação. Para esse autor, a atividade é entendida como um processo psicológico que tem origem em uma necessidade. Essa necessidade objetiva-se materialmente no motivo que incita o sujeito a agir, e este motivo, por sua vez, coincide com o que é objetivado por meio das ações desenvolvidas pelo sujeito em atividade. Ou seja, motivo e objeto devem coincidir na estrutura da atividade. Se uma atividade perde o seu motivo, ela se converte em uma mera ação. Por outro lado, se uma ação ganha um motivo próprio que a mova, então ela se converte em uma atividade. Esse movimento é característico da compreensão de atividade como um sistema dinâmico.

A transformação dos motivos da atividade só é possível quando se dá uma nova atribuição de sentido pessoal pelo sujeito, uma vez que segundo Leontiev o motivo está diretamente ligado ao sentido pessoal (Leontiev, 1983). Assim, a constituição de uma nova atividade, resultante da atribuição de novos sentidos pessoais às significações sociais, ou seja, da produção de novos motivos, só é possível na própria atividade do sujeito (Leontiev, 1983). O referido autor afirma:

\footnotetext{
A significação é a generalização da realidade que é cristalizada e fixada num vetor sensível, ordinariamente a palavra ou a locução. É a forma ideal, espiritual da cristalização da experiência e da prática social da humanidade. A sua esfera das representações de uma sociedade, a sua ciência, a sua língua existem enquanto sistemas de significação correspondentes (Leontiev, 1972, p. 100).
}

Tal conceito revela uma compreensão da constituição histórica e social do homem que se apropria das experiências das gerações precedentes, uma vez que "a significação é a forma pela qual um homem determinado chega a dominar a experiência da humanidade, refletida e generalizada" (Leontiev, 1983, p. 225).

Assim, a significação representa a generalização da experiência humana, e como fenômeno objetivamente histórico, não existe independentemente dos sujeitos.

Já o sentido pessoal, embora dialeticamente relacionado com a significação, está sempre ligado ao motivo que incita o sujeito a agir, portanto, também ao objeto para o qual suas ações estão direcionadas, uma vez que na atividade motivo e objeto coincidem.

Referindo-se a esse movimento entre motivos e sentidos na transformação da atividade dos sujeitos, Moretti e Moura (2010) concordam com Leontiev (1983)

quando esse autor defende que não é possível ensinar o sentido de algo, uma vez que o sentido é atribuído pelo 
sujeito no transcurso da atividade, no decorrer da própria vida. Assim, o sentido só pode ser educado em sua unidade com a significação social (p. 160).

Ainda segundo esses autores, a "implicação disso para a formação de professores é que as ações desencadeadas por estes no âmbito de tais propostas devem ter como referência direta o seu trabalho docente" (p.160). Neste contexto, no qual se tem como objetivo a organização do ensino para favorecer a aprendizagem dos estudantes e como referência a prática pedagógica, se a ação do sujeito coincidir com o seu motivo para agir, diremos que ele está em atividade de ensino.

$\mathrm{Na}$ pesquisa desenvolvida e apresentada neste artigo, a articulação proposta entre a fundamentação teórica que justifica as ações de pesquisa e a necessidade instaurada entre os estudantes de graduação de organizar o Clube de Matemática teve por objetivo criar condições para que estes entrassem em atividade de ensino, portanto, também em movimento de aprendizagem da docência.

\section{O Clube de Matemática}

O desenvolvimento das ações do Clube de Matemática deu-se por meio de atividade curricular não obrigatória para estudantes do curso de Pedagogia da universidade. Tal inserção curricular deu-se por meio da unidade curricular Práticas Pedagógicas Programadas (PPP). Entre os objetivos estabelecidos para esta disciplina no Projeto Curricular do curso de Pedagogia desta instituição destacam-se os de "proporcionar espaço para a aprendizagem prática dos pedagogos em formação" (Unifesp, 2010, p.42) e "proporcionar aos alunos elementos concretos para a reflexão sobre o fenômeno educacional na sua complexidade" (Unifesp, 2010, p.43).

Como forma de organização, a unidade curricular Práticas Pedagógicas Programadas oferece aos estudantes dos quatro primeiros semestres do curso diferentes linhas de trabalho, orientadas pelos professores que as propuseram. Os alunos inscrevem-se nas linhas a partir de seu interesse acadêmico, o que, como intenção pedagógica, alinha-se à noção de percurso formativo (Canário, 2000). Não há na grade curricular um horário específico para a atividade de orientação de PPP. Em geral, o professor coordenador da disciplina negocia com os demais docentes do curso um cronograma semestral de cinco encontros - de quatro horas cada um - que acontecem em forma de rodízio em dias alternados da semana no horário de aula dos estudantes, mas muitos orientadores de PPP combinam com o grupo de estudantes matriculados na linha por eles coordenada um horário diferenciado de encontros.

Embora a aproximação com uma prática profissional que considere as diversas frentes de trabalho do pedagogo seja objetivo claro nas propostas de PPP, há o cuidado para que essa aproximação se dê com base na teoria, de forma a permitir aos estudantes o planejamento e a avaliação das ações desenvolvidas, bem como "a construção de relações teórico-práticas alimentadas por um sentido político que desnaturaliza o ato educativo e o localiza no contexto atual com todas as suas dimensões" (Unifesp, 2010, p.43).

Neste contexto, propusemos aos estudantes a linha de PPP "Clube de Matemática", entendido este como espaço lúdico para a aprendizagem da Matemática. Tal proposta desenvolveu-se a partir da experiência análoga, já bastante consolidada, do Clube de Matemática da Faculdade de Educação da Universidade de São Paulo. Tal experiência tem contribuído para a compreensão da potencialidade do Clube de Matemática como espaço de aprendizagem de alunos e professores (Cedro, 2004; Lopes, 2004). Nela, toma-se o jogo como elemento desencadeador central das ações. Explicam Moura, Lopes e Cedro (2008, p. 131):

$\mathrm{Na}$ elaboração das atividades do Clube de Matemática o jogo é tomado a partir de uma definição ampla, como uma possibilidade de explorar um determinado conceito matemático que se apresenta para o aluno de forma lúdica [...]. Enquadra-se, portanto, nestas características: quebracabeças, brincadeiras, problemas-desafio, etc.

Em nosso caso, os jogos utilizados, em sua maioria, foram confeccionados por estudantes do curso de Pedagogia em uma disciplina do quinto semestre que aborda a metodologia do ensino da matemática. O objetivo principal da proposta foi desenvolver ações para a implementação de atividades do Clube de Matemática em uma escola da Prefeitura de Guarulhos parceira no desenvolvimento do Clube. Para isso, propusemos ações iniciais voltadas para as seguintes atividades: 1- estudo teórico sobre o elemento lúdico na aprendizagem matemática; 2- pesquisa de práticas vinculadas a esse espaço; e 3- organização de materiais e jogos produzidos por estudantes do curso de Pedagogia da Universidade no período de 2009 a 2011 para o ensino da Matemática na Educação Infantil e nas séries iniciais do Ensino Fundamental.

Em face da especificidade da proposta e da premência da realização de atividades na escola, foi acordado com os estudantes interessados nessa linha de pesquisa que realizaríamos encontros semanais, com uma hora de duração, entre os períodos vespertino e noturno, como forma de viabilizar a participação de estudantes de ambos os turnos.

Como os estudantes do Clube ainda não haviam cursado disciplinas relacionadas à metodologia e prática de ensino da matemática, houve a necessidade de uma aproximação teórica, ainda que breve, sobre o conceito de números e operações e seu ensino, assim como sobre o papel do jogo e do aspecto lúdico no ensino de matemática. De forma geral, o trabalho realizado pela linha Clube de Matemática junto aos estudantes pode ser descrito em três momentos, considerando-se o motivo da ação de formação proposta: 1- aproximação com o ensino de matemática: conceito de número e operações e papel no jogo; 2- conhecimento e organização dos materiais disponíveis para o Clube; 3- planejamento e avaliação das ações desenvolvidas com as crianças na escola parceira. 
A primeira ação proposta aos estudantes foi a busca de informações sobre a noção de Clube de Matemática, seus objetivos, instituições proponentes, práticas formativas, públicos, etc. Essa ação justificou-se pelo fato de que, como essa era uma proposta nova na nossa universidade, ainda não havia uma prática consolidada que pudesse servir de referência para os estudantes acerca das possibilidades pedagógicas do Clube de Matemática.

A partir das informações trazidas pelos estudantes veio à tona a questão do papel da ludicidade no ensino de Matemática. Tal discussão deu-se ancorada em elementos teóricos (Grando, 2004; Moura, 2006) relacionados aos fundamentos da Teoria Histórico-Cultural, tais como a mediação do parceiro mais capaz e o brincar como a atividade principal da criança (Leontiev, 2001), entendida essa atividade como "aquela cujo desenvolvimento governa as mudanças mais importantes nos processos psíquicos e nos traços psicológicos da personalidade da criança, em um certo estágio de seu desenvolvimento" (p.65).

Ainda visando à aproximação dos estudantes com temas relacionados ao ensino da Matemática, optamos por estudar elementos da produção do conceito de número e de sua aprendizagem (Ponte, \& Serrazina, 2000), destacando a estrutura do sistema de numeração decimal: base, valor posicional, número finito de signos e dupla função do zero (Dias, \& Moretti, 2010).

Em uma segunda etapa os estudantes tomaram contato com o material didático disponível para o Clube de Matemática e tiveram o desafio de analisá-los quanto aos conceitos envolvidos, à ludicidade, ao nível de dificuldade e ao seu estado de conservação. A etapa seguinte, a mais esperada pelos estudantes, a qual ocupou a segunda metade do semestre, consistiu no planejamento, organização, realização e avaliação das atividades desenvolvidas junto às crianças na escola parceira.

Cada etapa representou para os estudantes novos desafios, possibilitando-lhes diferentes aprendizagens relativas à atividade docente.

\section{Metodologia de coleta de coleta e análise de dados}

Os participantes do Clube de Matemática elaboraram um relatório final coletivo e um portfólio reflexivo, os quais serviram como fonte de dados para esta pesquisa. Villas Boas (2004, p. 38) entende portfólio como

(...) uma coleção de suas produções (do aluno), as quais apresentam as evidências de sua aprendizagem (do aluno). É organizado por ele próprio para que ele e o professor, em conjunto, possam acompanhar seu progresso. O portfólio é um procedimento de avaliação que permite aos alunos participar da formulação dos objetivos de sua aprendizagem e avaliar seu progresso. Eles são, portanto, participantes ativos da avaliação, selecionando as melhores amostras de seu trabalho para incluí-las no portfólio.
Escolhemos o portfólio reflexivo como instrumento de autoavaliação dos estudantes por entendermos que a utilização desse instrumento, assim como sua análise, pode ser coerente com a perspectiva teórica adotada (Araújo, 2007), uma vez compreendida a linguagem como "a função central das relações sociais e da conduta cultural da personalidade" (Vygotski, 2000, p.148). Além disso, a unidade dialética entre a inteligência prática e o uso de signos é indicada por Vigotski (Vygotski, 2000) como a essência do comportamento humano complexo. Para esse autor, atribui-se "à atividade simbólica uma função organizadora específica que invade o processo do uso de instrumentos e produz formas fundamentalmente novas de comportamento" (Vigotski, 2002, p. 32-33).

Nesse sentido, Araújo (2007) explicita a possibilidade de o portfólio reflexivo favorecer o processo de internalização de ações produzidas no coletivo, uma vez que a

(...) produção do portfólio tem sua gênese na interação com os outros, na ação externa, o que não dispensa o processo de auto implicação de quem o produz. Ou seja, na produção do portfolio reflexivo, dá-se a relação dialética entre o inter e o intrapessoal (p.3).

Vale destacar que os alunos foram informados da pesquisa sobre a aprendizagem de elementos da docência em Matemática no Clube de Matemática e consentiram na análise do material produzido, para fins da pesquisa ${ }^{1}$. Embora o grupo fosse constituído de seis estudantes, na análise dos dados optamos por focar os de quatro estudantes, considerando sua assiduidade. Consideramos importante esse um critério, uma vez que a pesquisa os acompanhou por um semestre letivo.

Todas as estudantes tinham entre 19 e 23 anos e cursavam o segundo ano do curso de Pedagogia. Além disso, indicaram ter escolhido participar do Clube de Matemática com o objetivo de conhecer formas diferenciadas de abordar a Matemática, uma vez que, como futuras professoras, gostariam de ensiná-la de forma diferente daquela que aprenderam.

Para a análise dos dados foram selecionados excertos dos textos produzidos pelos estudantes que indicassem o movimento de aprendizagem de elementos da docência em Matemática, considerando-se, conforme indicado anteriormente, o papel da linguagem e a relação entre as atividades inter e intrapessoal possibilitada por esse instrumento. $\mathrm{Na}$ apresentação dos excertos, sua autoria e fonte são indicados entre parênteses.

\section{Análise: A aprendizagem de elementos da docência em Matemática}

O Clube de Matemática possibilitou a aproximação dos estudantes com a atividade do professor, ainda que de forma inicial. Ao se depararem com a necessidade de prepa-

1 Visando preservar a identidade dos estudantes, utilizamos nomes fictícios na indicação de autoria dos excertos selecionados do material para a análise dos dados. 
rar os encontros com as crianças na escola, os estudantes desenvolveram ações de planejamento que foram avaliadas por eles próprios depois de cada ida à escola. Nesse momento, sentiram a necessidade da reorganizar suas ações tendo em vista a prática escolar:

Nessa primeira ida eu pude constatar uma coisa que eu já imaginava, as crianças apresentam graus diferentes de desenvolvimento [...] então ficou claro que seria importante levarmos alguns jogos mais simples para aqueles alunos que apresentaram maior dificuldade (Portfólio Marta).

O material é muito bom, mas tivemos que adaptar alguns jogos [...] Além disso, também preparávamos material para o próximo encontro, tentando sempre nos aproximarmos mais das necessidades dos alunos e do que eles gostavam (Portfólio Cris).

Nossas ações também contaram com contratempos e imprevistos como em todo projeto que envolve decisões no transcorrer do caminho, os quais demandaram uma série de reorganizações e readaptações em nosso percurso. Um exemplo interessante a ser citado refere-se a uma nova seleção de jogos mais fáceis ou mais difíceis após um primeiro contato com a turma, em que nos norteamos pelas habilidades apresentadas pelos alunos (Relatório coletivo).

As ações dos estudantes de organizar o Clube, que num primeiro momento partiram da demanda da docente $\mathrm{e}$ estiveram vinculadas à proposta inicial da linha de estudo, transformaram-se em atividade para o sujeito quando ganharam um motivo e, desta forma, um sentido pessoal. Em outras palavras, as ações transformaram-se em atividade de ensino para os estudantes quando tais ações passaram a ser motivadas pela avaliação dos próprios estudantes acerca das reais necessidades de aprendizagem e ludicidade demonstradas pelas crianças na escola.

Neste contexto, a reorganização das ações foi identificada pelos estudantes como uma necessidade na organização do ensino apenas na relação estabelecida com a realidade escolar objetivada no contato com os alunos na escola. Ocorrências inesperadas no decorrer da ação planejada levaram os estudantes a um primeiro momento de insegurança e, em seguida, ao reconhecimento da necessidade de reorganização, como podemos ver no excerto abaixo:

Embora nós tenhamos tido um tempo razoável para planejar as atividades, ainda apareciam casos fora do esperado [...] ele [aluno] não conseguia nem ao menos fazer a relação do número com o objeto concreto, correspondência um a um [...] não conseguia estabelecer uma relação entre o número que ele falava e o dedo, de modo que juntava todos ao contar [...] ele conseguiu participar melhor no segundo dia, talvez por ter havido uma reorganização em função da dificuldade que ele apresentou, mas o que me chamou atenção no caso dele é que nesse segundo dia ele conseguiu realizar a correspondência (Portfólio Marta).
As novas ações desenvolvidas no segundo encontro com as crianças, produzidas a partir do resultado da ação anterior, na realidade objetiva, dão indícios da unidade dialética entre a atividade interna e atividade externa tal como compreendida no campo de análise da Psicologia Histórico-Cultural, e particularmente, das contribuições de Leontiev (1983). Esse autor propõe que a atividade teórica interna e a atividade prática externa dos sujeitos mantêm a mesma estrutura geral. Assim, a atividade interna, "que se origina a partir da atividade prática externa, não se separa dela, mas conserva uma relação fundamental e bilateral com a mesma" (p. 83).

Além disso, ao criar uma possibilidade de aproximação com o ensino da Matemática mediante a organização de situações de aprendizagem para as crianças baseadas na ludicidade e no jogo, o Clube de Matemática acabou possibilitando que as próprias estudantes da graduação revisitassem sua relação com a Matemática e seu ensino. Uma das estudantes começa seu portfólio afirmando:

Eu não gosto de matemática, e posso até falar que temo um pouco o tema [...] (Portfólio Cris).

Não obstante, no decorrer de sua atividade no Clube de Matemática, a estudante vai mostrando o despertar do interesse por estratégias de ensino diferenciadas para a área, em especial a utilização de jogos para o ensino da Matemática:

[...] jogo não se limita apenas a uma brincadeira ou passatempo. Quando bem utilizado ele desenvolve várias questões a quem o pratica. No caso de crianças ele desenvolve também as interações sociais, solidariedade, a criança deixa de lado seu egocentrismo para ajudar o colega, possibilita a criança superar suas limitações [...] possibilita a quem joga uma auto avaliação sobre seu desempenho (Portfólio Cris).

O conhecimento dessas novas possibilidades didático-pedagógicas permitiu que na experiência no Clube de Matemática Cris ressignificasse seu temor em relação à Matemática. Ela finaliza o portfólio avaliando:

O saldo dessa PPP [Clube de Matemática] é muito acima de positivo. Adorei ter participado, foi enriquecedor para mim e para minha formação. Espero verdadeiramente que ela continue e dê oportunidade para outros alunos [a] conhecerem (Portfólio Cris).

Outro elemento que se explicitou na análise do material produzido pelas estudantes foi a importância dada por elas à relação entre teoria e prática e à necessária articulação entre ambas. Embora a necessidade dessa articulação seja bastante evidente a partir do referencial teórico que fundamenta a pesquisa, foi na própria atividade de ensino que as estudantes atribuíram sentido pessoal a essa relação e apresentaram indícios de sua internalização: 
Essa grande quantidade de readaptações, mesmo após as discussões teóricas e todo o planejamento, nos surpreenderam muito, pois se tratam de detalhes aos quais não demos tanta ênfase inicialmente, concebendo-os como passíveis de "improvisos" quando necessário. Percebemos assim a grande dicotomia que há entre teoria e prática no exercício da docência (Relatório coletivo).

Essa PPP foi diferente das outras, pois teve uma proposta muito mais dinâmica. A maioria dos professores peca ao se preocupar apenas com a teoria. A teoria é sim importante, mas tão importante quanto, é a prática. A PPP é uma excelente oportunidade que temos de juntar teoria e prática (Portfólio Cris).

O sentido sobre o trabalho do professor e suas condições concretas de objetivação também se apresentou como elemento de aprendizagem para as estudantes no Clube de Matemática. No contexto da reorganização das ações, Marta reconhece quanto esse movimento demanda tempo do professor, tempo que é condição para viabilizar o trabalho docente. Nesse sentido, essa estudante estabelece relação entre essa necessidade e as reais condições de trabalho da maioria dos professores:

Recordei que uma das principais reclamações dos professores é a falta de tempo para planejar suas atividades, pois costumam trabalhar em mais de uma escola. Seria muito bom se houvesse esse tempo para planejar as atividades, mas infelizmente os professores ainda precisam trabalhar com jornadas duplas para compor um salário que atenda, ainda que não totalmente, suas necessidades financeiras (Portfólio Marta).

Outras estudantes abordaram de forma indireta a dificuldade do professor em trabalhar com um número grande de alunos em sala de aula, seja por conta da heterogeneidade do grupo seja pela restrição que essa condição acaba impondo à implementação de estratégias didáticas que impliquem maior mediação, como por exemplo, a utilização de jogos:

Todas essas apreensões servem para caracterizar o quanto heterogênea é a sala [...] e indica a complexidade da responsabilidade do professor diante de uma sala de aula como essas, nos dando indícios do que teremos pela frente no nosso curso e na nossa carreira e concretizando as análises teóricas trabalhadas até então [...] (Portfólio Cleo).

Uma pena que uma hora eu fiquei com um grupo grande no qual as meninas vieram pra jogar e o grupo que estava lá queria terminar, e eles acabaram brigando [...] Foi ai que percebi a dificuldade que é para apenas uma professora na sala de aula, levar diversos jogos para as crianças, pois envolve uma certa atenção com as crianças e precisa de mais de uma pessoa para ajudar no processo de mediação (Portfólio Ariel).
Mais do que o discurso teórico sobre as dificuldades cotidianas do professor, as demandas criadas pelo Clube permitiram às estudantes compreenderem o impacto de tais condições - ou ausência delas - na atividade docente. Novamente a relação entre a teoria e a prática, ao ser viabilizada na formação inicial de professores, cria condições para a atribuição de novos sentidos e, como consequência, de novas aprendizagens.

\section{Considerações finais}

Ao tomarmos como objeto de investigação a aprendizagem de elementos da docência em Matemática em estudantes do curso de Pedagogia que participaram do Clube de Matemática em uma universidade pública paulista, fizemo-lo a partir da Teoria Histórico-Cultural. Tal referencial ao mesmo tempo nos forneceu elementos teóricos para a análise do fenômeno da formação inicial desencadeado nos espaços formativos e orientou-nos nas tomadas de decisão e na organização das ações de formação. Neste sentido, a opção da professora formadora responsável pelo Clube pelas ações formativas que resultaram no percurso proposto aos estudantes ancora-se nos conceitos essenciais da teoria já retomados neste texto. Em particular, a questão da mediação, da criação da necessidade que move o sujeito para a atividade - de ensino ou de aprendizagem - e a articulação entre a teoria e a prática nortearam a escolhas das ações propostas no Clube de Matemática.

A análise da produção das estudantes revela que no percurso que thes foi proposto desencadeou-se a aprendizagem de elementos da docência e, em particular, da docência em Matemática. Assim, evidenciou-se que na atividade coletiva, diante da necessária articulação entre a teoria e a prática inerente à proposta do Clube de Matemática, as estudantes analisadas atribuíram novos sentidos à reorganização de ações na atividade de ensino e sua relação com o planejamento da atividade; à sua relação com a Matemática e seu ensino, à relação entre a teoria e a prática na organização do ensino e ao trabalho do professor e suas condições objetivas.

Embora não seja possível afirmar a coincidência entre os novos sentidos e a significação social, o movimento de atribuição de novos sentidos desencadeado pelas necessidades postas aos sujeitos - os quais se encontravam em formação inicial para a docência -, revela um movimento de transformação das atividades e aponta para o movimento de aprendizagem e formação docente em atividade de ensino, indicando a possiblidade e a relevância de novos estudos longitudinais sobre a relação entre sentidos pessoais, significação social e aprendizagem da docência.

\section{Referências}

Asbahr, F. S. F. (2011) Por que aprender isso, professora? Sentido pessoal e atividade de estudo na Psicologia Histórico-Cultural. Tese de Doutorado, Universidade de São Paulo, São Paulo-SP. 
Araújo, E. S. (2007). O uso do portfólio reflexivo na perspectiva histórico-cultural. Trabalho apresentado na $30^{\text {a }}$ Reunião Anual da Anped, Caxambu - MG.

Canário, R. (2000). A prática profissional na formação de professores. Trabalho apresentado no Colóquio Formação Profissional de Professores no Ensino Superior, Aveiro.

Cedro, W. L. (2004). O espaço de aprendizagem e atividade de ensino: o clube de matemática. Dissertação de Mestrado, Universidade de São Paulo, São Paulo.

Dias, M. S., \& Moretti, V. D. (2010). Números e operações: elementos lógico-históricos para atividade de ensino. Curitiba: Ibpex.

Grando, R. C. (2004). O jogo e a matemática no contexto da sala de aula. São Paulo: Paulus.

Leontiev, A. (1972). O desenvolvimento do psiquismo. São Paulo: Editora Moraes.

Leontiev, A. (1983). Actividad, Conciencia, Personalidad. Ciudad de La Habana: Editorial Pueblo Y Educación.

Leontiev, A. N. (2001). Uma contribuição à teoria de desenvolvimento da psique infantil. Em Vigotskii, L. S., Luria, A. R., \& Leontiev, A. N. Linguagem, desenvolvimento e aprendizagem. (Cap.4, pp. 59-83). São Paulo: Ícone.

Lopes, A. R. L. V. (2004). A aprendizagem docente no estágio compartilhado. Tese de Doutorado. Universidade de São Paulo, São Paulo.
Moretti, V. D., \& Moura, M. O. (2010). O sentido em movimento na formação de professores de matemática. Zetetiké, 18(34), 155180.

Moretti, V. D., Asbahr, F. S. F., \& Rigon, A. J. (2011). O humano no homem: os pressupostos teórico-metodológicos da teoria históricocultural. Psicologia e Sociedade. 2011, 23(3), 477-485.

Moura, M. O. (2006). A séria busca no jogo: do lúdico na matemática. Em Kishimoto, T. M. (Org). Jogo, brinquedo, brincadeira e a educação. (pp. 73-87). São Paulo: Cortez.

Moura, M. O., Lopes, A. R. L. V., \& Cedro, W. L. (2008). A formação inicial de professores que ensinam matemática: a experiência do Clube de Matemática. Revista da Educação, XVI (2), 123 - 137.

Ponte, J. P.. \& Serrazina, M. L. (2000). Didáctica da Matemática do $1^{\circ}$ ciclo. Lisboa: Universidade Aberta.

UNIFESP (2010). Projeto Pedagógico do Curso de Pedagogia. São Paulo, SP: EFLCH-Unifesp.

Vigotskl, L. S. (2002) A formação social da mente. São Paulo: Martins Fontes.

Vigotski, L. S. (2000). A construção do pensamento e da linguagem. São Paulo: Martins Fontes.

Villas boas, B. M. F. (2004). Portfólio, avaliação e trabalho pedagógico. Campinas, SP: Papirus.

Vygotski, L. S. (2000) Obras escogidas, Vol. 3. Madrid: Visor.

\section{Sobre a autora}

Vanessa Dias Moretti (vanessa.moretti@unifesp.br)

Doutora em Educação. Universidade Federal de São Paulo. 